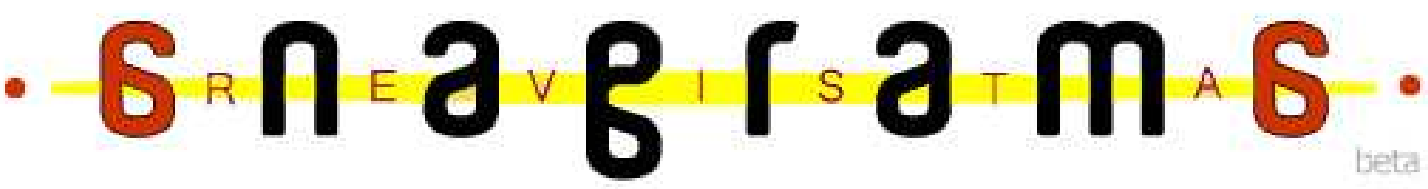

\section{Branding $360^{\circ}$ em Telenouela}

Dhione Oliveira Santana ${ }^{1}$

Raquel Marques Carriço Ferreira?

\section{Resumo}

O presente artigo nasceu da necessidade de avaliar de forma detalhada as mudanças ocorridas nas embalagens Lukscolor ${ }^{\circledR}$ que foram feitas pela agência Design Absoluto e comunicadas, principalmente, através de ações de merchandising inseridas na telenovela Insensato Coração. A pesquisa foi baseada na proposta de Lúcia Santaella (2002) que aponta três pontos fundamentais da análise semiótica, bem como foram feitas também revisões bibliográficas sobre as telenovelas, comunicação mercadológica, branding e design de embalagens para conceituar nosso objeto de pesquisa.

Palauras-chaue: Telenovelas; Semiótica; Merchandising; Comunicação e Marketing; Branding; Design de Embalagens.

Introdução:

As telenovelas são indiscutivelmente uma das maiores fontes de entretenimento dos brasileiros, "o único teatro, cinema e - por que não? - literatura de uma massa considerável que não tem acesso à arte de elite (CAMPEDELLI, 1977)”. Considerando que além de entreterem os telespectadores as telenovelas tornam-se um ótimo instrumento de persuasão quando são inseridas ações comerciais. Tal fato vem propiciando pesados investimentos do mercado publicitário no patrocínio de blocos comerciais e em ações de merchandising.

${ }^{1}$ Estudante do $4^{\circ}$ período de Publicidade \& Propaganda da Universidade Federal de Sergipe (UFS), Bolsista do PIIC Programa de Inclusão á Iniciação Científica.

${ }^{2}$ Orientadora do trabalho. Doutora em Televisão e Cinema pela Universidade Nova de Lisboa, Professora do Curso de Publicidade e Propaganda da Universidade Federal de Sergipe, UFS. email: raquelcarrico@ gmail.com. 
De acordo com CAMPEDELLI (1977) ao se pensar a telenovela, dentre outras características, podemos ponderar que sua estrutura é constituída por vários micro-enredos denominados multiplots que giram ao redor de um plot (enredo) principal. Outra característica é a presença de "ganchos", ou seja, de momentos ápice que tem o objetivo de prender a atenção do telespectador antes de um bloco comercial e/ou do final do capítulo, despertando assim, o interesse no acompanhamento da estória.

Devido ao grande sucesso do gênero, a telenovela Insensato Coração da Rede Globo (2011) foi escolhida para comunicar, através do merchandising, todo o processo de mudanças de identidade visual das embalagens que as tintas Lukscolor ${ }^{\circledR}$ estavam passando. As ações foram inseridas no plot trabalho da protagonista Marina (Paola Oliveira), ao todo foram exibidas quatro ações entre os meses de março a junho de 2011.

O presente artigo nasceu da necessidade de avaliar de forma detalhada as mudanças ocorridas nas embalagens Lukscolor ${ }^{\circledR}$ que foram feitas pela agência Design Absoluto e comunicadas, principalmente, através de ações de merchandising inseridas na telenovela Insensato Coração. A pesquisa foi baseada na proposta de Lúcia Santaella (2002) que aponta três pontos fundamentais da análise semiótica, bem como foram feitas também revisões bibliográficas sobre as telenovelas, comunicação mercadológica, branding e design de embalagens para conceituar nosso objeto de pesquisa.

\section{A Embalagem:}

\section{Breve Panorama Geral:}

De acordo com NEGRÃO E CAMARGO (2008) apud TOGA (1985, p. 25), a necessidade de embalar produtos começou a aparecer á medida que a vida do homem tornou-se gradativamente mais complexa; quando amadureceu a consciência de que passou a ser preciso armazenar; quando aumentou a distância entre sua moradia permanente ou semi-permanente - provavelmente a caverna - e suas fontes de abastecimento.

Segundo MOURA \& BANZATO (1990) apud ROMANO (pág. 06, 1996), ao longo da história as embalagens passaram por três fases:

I) a primeira fase compreende o período desde o surgimento do homem, até aproximadamente 4000 a.C.. Esta fase apresenta uma época onde inicialmente as embalagens não eram confeccionadas, isto é, os primitivos usavam, por exemplo, objetos 
oferecidos pela natureza, como chifres, peles ou bexigas de animais, bem como a confecção de cestos rudimentares;

II) na segunda fase, que compreende desde 4000 a.C. até aproximadamente 1760 d.C., observa-se o surgimento das embalagens propriamente ditas, inicialmente usadas no intercâmbio de mercadorias entre o Egito e a Mesopotâmia (p.ex.: recipientes de argila, de alabastro, etc..); .

III) na terceira fase, de 1760 d.C. até os tempos atuais, verifica-se a caracterização das embalagens às funções de proteção, ilustração e venda (p.ex.: garrafas de vidro).

A palavra embalagem é etimologicamente associada ao verbo embalar - fato que deve as suas funções primordiais na sua primeira fase histórica: à de proteger e carregar. Na visão de NEGRÃO e CAMARGO (2008), a embalagem hoje não só tem a finalidade de proteger e transportar, possuindo novas funções que a tornaram mais importante e valorizada, tais como: ser funcional, identificar, informar, formar e consolidar imagem, promover, vender, agregar valor, etc.

Sendo assim, devido todas as funções adquiridas, ao longo de sua história, define-se "embalagem como: um sistema cuja á função é técnica e comercial que tem como objetivos acondicionar, proteger (desde o processo de produção até o consumo), informar, identificar, promover e vender um produto (NEGRÃO e CAMARGO, pág. 29, 2008)”.

\section{Estado da Arte:}

Apesar de o tema chamar à atenção de diversos profissionais que vão desde engenheiro de produtos até administradores, hoje, no Brasil, existe uma modesta produção acadêmica sobre o estudo da embalagem. Iniciativas como o $3^{\circ}$ Fórum Nacional de Gestão Estratégica de embalagem, coordenado pelo Núcleo de Estudos da Embalagem da ESPM, têm contribuído para a fomentação a discussões teórica sobre o assunto no país. Sendo assim, o presente artigo vem contribuir de forma modesta para o enriquecimento da literatura acadêmica sobre o assunto no Brasil.

\section{Projeto Branding $360^{\circ}$}

O projeto Branding $360^{\circ}$, das tintas Lukscolor, consistiu em uma série de mudanças na programação visual das suas embalagens e na sua marca, que teve o objetivo de torná- 
las mais modernas, interativas e destacadas nos pontos-de-venda. Desenvolvido em paralelo ao um processo de merchandising em Insensato Coração, as mudanças representaram uma evolução para marca.

De acordo com POLIGNANO e DRUMOND (2001), o desenvolvimento de produtos orientados para o mercado, imprescindível para empresas que almejam um desempenho diferenciado, exige o aperfeiçoamento contínuo dos processos associados à compreensão do mercado e ao planejamento da linha de produtos. Uma pesquisa de mercado adequada, para o desenvolvimento de novas embalagens, torna-se vital para alcançar o sucesso almejado.

Para que o desenvolvimento da nova identidade visual da Lukscolor ocorresse, seis meses antes da primeira ação de merchandising, foi feita uma pesquisa de mercado com os diversos púbicos que a marca se relaciona (consumidores, revendedores, especificadores e aplicadores) pelo Núcleo de Estudos da Embalagem da Escola Superior de Propaganda e Marketing (ESPM) que permitiu uma maior compreensão do mercado, servindo assim como base para o desenvolvimento criativo do projeto pela Agência Design Absoluto.

A pesquisa apontou que a Lukscolor ${ }^{\circledR}$ é uma das três marcas mais lembradas do mercado de tintas brasileiro. Os resultados também identificaram que as embalagens de tintas disponíveis no mercado não possuíam informações coesas e objetivas sobre os produtos e que o consumidor não conseguia entender as diferenças e vantagens existentes entre uma tinta econômica, standard e premium. .

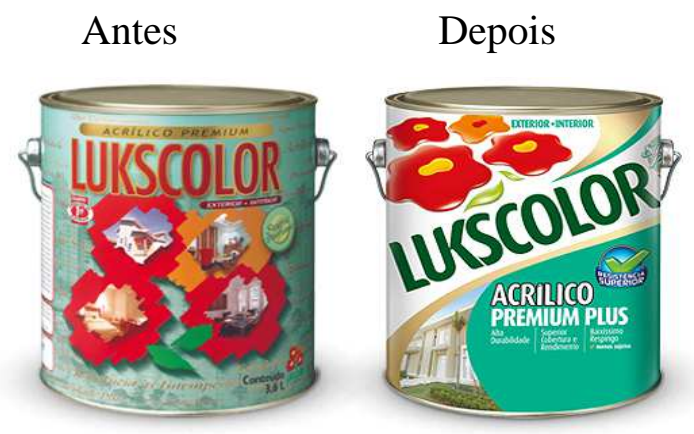

Antes e Depois das Embalagens Lukscolor, Disponível em: http: <//www.lukscolor.com.br/>

Baseado nos resultados da pesquisa e inspiradas nas obras artísticas de Paul Jackson Pollock a construção imagética, apresenta assim, referências do movimento expressionista abstrato alemão. Segundo o dicionário eletrônico Michaelins o expressionismo abstrato 
alemão foi um movimento cultural-artístico de vanguarda que tinha como característica a subjetividade e a reflexão individual.

\section{Semiótica Peirciana: Categoria dos Gêneros}

O estudo dos signos, da significação e de todos os tipos de linguagem denominado semiótica é muito antigo, apresentando várias correntes, o presente trabalho destaca a corrente peirciana, que segundo SANTAELLA (1992) não é uma ciência aplicada e nem uma ciência teórica especial, ou seja, especializada. "A semiótica, ou lógica, é uma ciência forma abstrata, num nível de generalidade ímpar" (SANTAELLA, pág. 43, 1992).

Apesar da corrente semioticista peirciana não ser uma ciência aplicada (ver SANTAELLA, 1992), ela pode ser utilizada para analisar qualquer signo, porém, na visão própria SANTAELLA (2007) aplicar a teoria da semiótica peirciana não é uma tarefa fácil, "especialmente quando falta um conhecimento mais profundo dos fundamentos e implicações destes conceitos” (SANTAELLA, 2007, pág. Pág. 15). Realidade que aumenta ainda mais a responsabilidade de qualquer pesquisador que quer aplicar esta vertente da teoria dos signos.

Afinal de contas o que é um signo? Seria um fenômeno da astrologia? Não, segundo SANTAELLA (2004) signo é igual linguagem, por isso, que se define semiótica como o estudo de todos os signos ou de todas as linguagens. Complexo e muito abstrato, o pensamento de Charles Sanders Peirce (1839-1914) alicerça-se sobre três categorias fenomenológicas capazes de englobar tudo o que é, tudo o que pode ser e tudo o que tende a ser (ALMOZA, pág. 2, 2001).

\footnotetext{
"Essas categorias irão para o que poderíamos chamar de modalidades possíveis de apreensão de todo e qualquer objeto (...), certamente há infinitas gradações entre essas modalidades. Elas se constituem, no entanto, nas modalidades mais gerais, através dos quais se opera apreensão-tradução dos fenômenos (SANTAELLA, pág. 42, 2004).
}

As três categorias do gênero aparecem na nossa consciência como representações mentais. Primeiridade (ícone) o signo estabelece relações consigo mesmo; secundaridade (índice), quando o signo torna-se uma extensão física do objeto; terceiridade (simbólico), quando apresenta o objeto como algo arbitrário cada observado pode criar uma imagem 
mental. Estas categorias, vale ressaltar, não são necessariamente excludentes, mas complementares.

\section{Aplicabilidade das Categorias dos Gêneros no Estudo das nouas Embalagens:}

Na visão de SANTAELLA (2002) a análise semiótica quando aplicada no design e/ou propaganda, tem como objetivo extrair dos mesmos os máximos das suas forças comunicacionais. Explorar através da análise, os efeitos e impressões que o produto, peça ou imagem pode causar ao receptor podem causar desde um nível de primeira impressão, até mesmo ao um nível de julgamento de valor.

Baseada na teoria da semiótica peirciana, fundamentada na réplica analítica de SANTAELLA (2002), o objetivo do trabalho foi o de analisar as relações das três categorias do Gênero nas Novas Embalagens da marca Lukscolor.

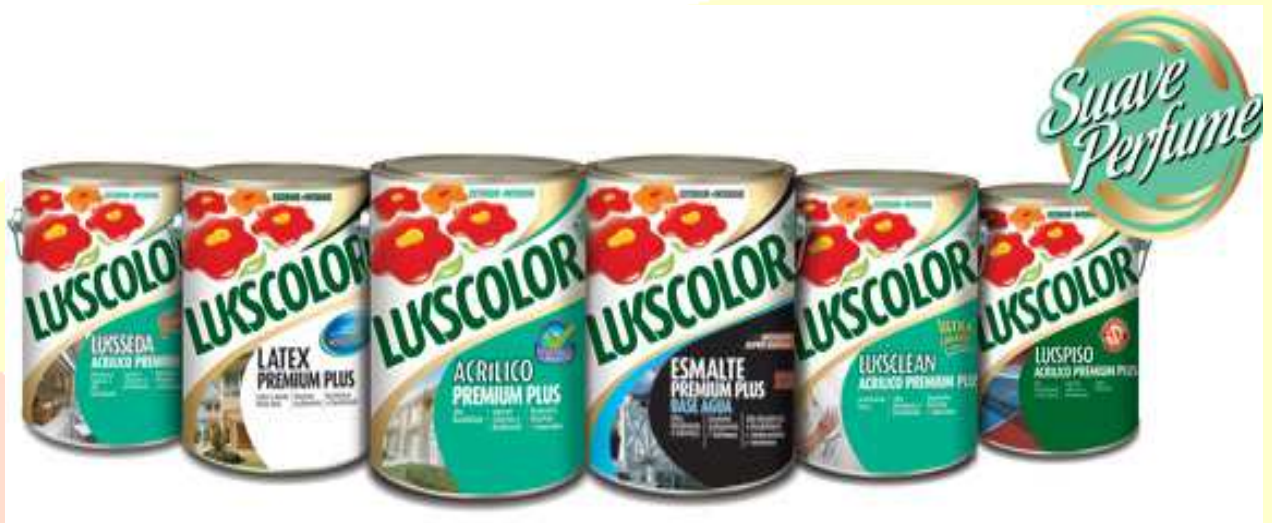

Título: Novas Embalagens Lukscolor. Fonte: http: <//www.lukscolor.com.br/>

Neste estudo, para fazer-se uma análise qualitativa sobre a evolução desta marca, optou-se por analisar especificamente a nova embalagem do produto LUKSCOLOR ${ }^{\circledR}$ ACRÍLICO PREMIUM PLUS.

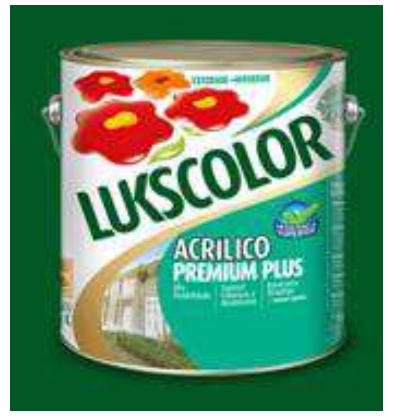

Título: Nova Embalagem Lukscolor Acrílico Plus. Fonte: http: <//www.lukscolor.com.br/> 


\section{Pontos de Vista Icônico (Primeiridade):}

Sob este ponto de vista, analisaremos os aspectos qualitativos da imagem do produto, ou seja, as cores, a distribuição dos elementos plásticos tais com: logotipo, linha e a forma. "Esses aspectos são responsáveis pela primeira impressão que um produto provoca no receptor [...] ou seja, as características que podem ser percebidas nas qualidades [...] tão sugerem qualidades abstratas, tais como leveza, força e monotonia". (SANTAELLA, Pág. 70, 2002).

"Numa embalagem a cor é o fator que, em primeiro lugar, atinge o olhar do consumidor (FARINA, Pág. 91, 1986)". As cores predominantes na nova embalagem do produto LUKSCOLOR ${ }^{\circledR}$ ACRÍLICO PREMIUM PLUS são: o branco, o verde, dourado, vermelho e laranja. A forma é cilíndrica, simétrica e totalmente geométrica. A distribuição dos elementos está interagindo com a distribuição dos elementos plásticos, apresentando traços que denotam sensações abstratas de harmonia e leveza, provocando um belo efeito visual nos pontos-de-venda.

O logotipo apresenta em formato 3D de forma ascendente, as cores são vermelhas e laranjas, cria-se uma ilusão ótica de volume, apresentando uma evolução para a marca. O logotipo também apresenta em verde uma fonte de letras exclusiva para a marca, trazendo personalidade e força.

A linha constitui um elemento plástico que "onde quer que seja utilizada, é um instrumento fundamental da pré-visualização, o meio de apresentar, em forma palpável, aquilo que ainda não existe, a não ser a imaginação" (DONDIS A ADONIS, pág. 56, 1997). O posicionamento das linhas proporcionam dinamismo, ritmo e elegância ao produto. Destaque para linha vertical dourada de todos os produtos que serve de suporte para o logotipo. Os símbolos icônicos fazem uma alusão direta ao objeto no mundo real, os únicos objetos identificáveis comuns em todas as embalagens são aqueles na qual há uma relação direta com modernidade.

\section{Pontos de lista Indicial (Secundaridade):}

Sob este ponto de vista, analisaremos os traços da identidade do produto, o contexto a que ele pertence, as funções, as finalidades a que se presta e a adequação do aspecto qualitativo-icônico com este segundo contextual. 


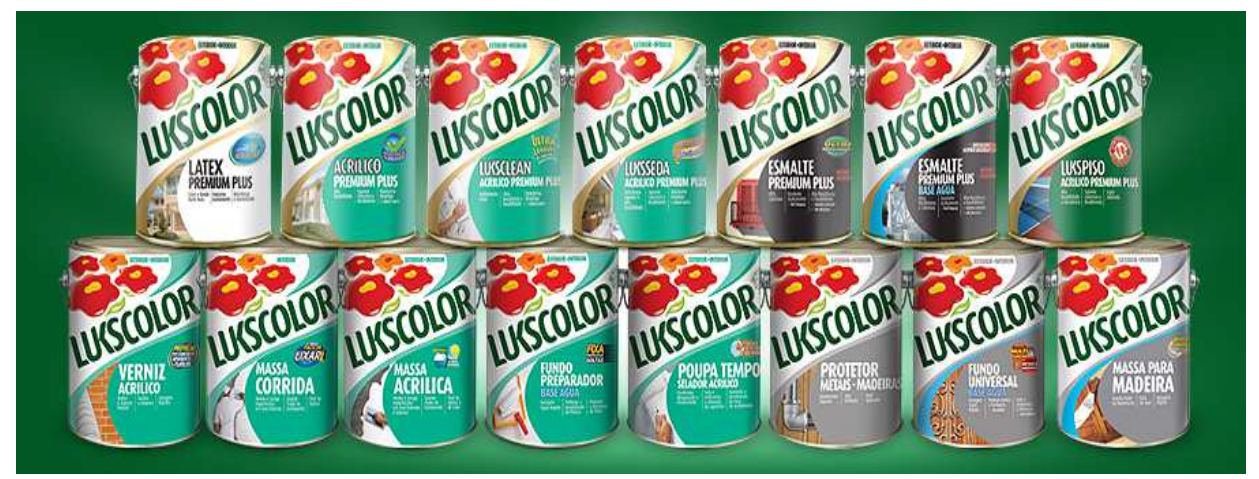

Título: Novas Embalagens Lukscolor. Fonte: http: <//www.lukscolor.com.br/>

O nome da marca LUKSCOLOR, funciona como índice, pois representa o conteúdo que está nas embalagens Luks igual à luz; e color igual à cor. As cores verdeescuro, verde-piscina, preta, cinza e branca nas embalagens tem função indicial servindo de traço distintivo, pois, representa a categoria a qual o produto dentro da lata pertence. A imagem presente entre a logo marca e o nome do produto que é uma casa, um piso, uma parede na maioria dos casos, também funciona como índice por causa expõe ao consumidor onde deve ser utilizado.

\section{O Ponto de Vista Conuencional-simbólico (Terceiridade): O Padrão de Distribuição da Informação:}

As embalagens apresentam um padrão constante em todas as embalagens que é rigorosamente seguido, esta padronização teve a finalidade de facilitar o entendimento do consumidor. Os signos plásticos nas novas embalagens foram reorganizados, para deixar as informações mais claras e didáticas destacando todos os benefícios do produto e mostrar as supostas vantagens de utilizar os produtos da marca.

A reorganização apresenta um primeiro conjunto de informações que é composto, na parte superior esquerda onde é apresentado o logotipo com o nome da marca e a ilustrações simbólicas de flores foi criado para trazer a ilusão de perfume, de preservação do meio ambiente. A tipografia da marca LUKSCOLOR é única e ascendente, foi criada para reforçar a ideia que a marca é única, a próprio nome da marca traz simbologicamente a sensação de luz e cor. 


\section{Inspiração Expressionista Abstrata:}

Jackson Pollock seria “o 'pai' da performance, aquele que, numa atividade corporal libertária introduziu definitiva e concretamente o sujeito da ação, o sujeito-artista, na estrutura da obra, tornando-se ele mesmo, matéria da obra" (CANONGIA, 2005, p. 13). As embalagens possui uma formação imagética que nos lembra uma obra de arte, o desenho da flor do logotipo ganha muito destaque, toda desempenho visual expressa uma subjetividade e permite uma reflexão individual.

\section{Considerações Finais:}

Tendo em vista a grande dificuldade de chamar à atenção do consumidor, as organizações viram nas telenovelas um terreno fértil para inserirem ações promocionais nos enredos. Com o objetivo de divulgar de forma lenta e gradual todo um processo de mudança na programação visual das suas embalagens à LUKSCOLOR utilizou da telenovela Insensato Coração para posicionar no mercado como uma marca que estava passando por uma evolução na sua identidade, para tornar mais destacada nos pontos de vendas.

Depois se analisar semioticamente as mudanças nas embalagens da Lukscolor, verificou-se que todo e qualquer signo possuem três tipos de significância: a icônica a expressão objetiva do signo, o indicial o signo pode ser tomado, em uma relação de causa e efeito, como representação de uma segunda coisa e o signo simbólico pode ser considerado como a expressão máxima da síntese informativa, a relação com o objeto é arbitrária, regida por uma norma social. As mudanças na identidade visual permitiram com que essas três significâncias reforçasse o poder da marca, atingindo o objetivo final de destacar o produto nos pontos de vendas.

Por fim, as mudanças de identidade visual da Lukscolor e as ações de merchandising feitas na telenovela Insensato Coração, combinaram, de forma inédita, a necessidade de mudar as embalagens ao mesmo tempo em que se tinha a necessidade de transmitir uma evolução e não uma mudança da marca, posicionando-se como uma marca forte no mercado. 


\section{REFERÊกCIAS BIBLIOGRÁFICAS}

BD-XPERT, portal. Marina de Insensato Coração redesenha a marca Lukscolor. Disponível em: $<$ http://www.bdxpert.com/2011/05/27/marina-de-insensato-coracao-redesenha-marca-real-dalukscolor/>. Acesso em: 15 de outubro de 2011.

BUDAG, F. E. (2008) Comunicação, Recepção e Consumo: suas inter-relações em Rebelde - RBD. Dissertação de Mestrado. São Paulo: Escola Superior de Propaganda e Marketing.

CALZA, Rose. O que é telenovela. São Paulo: Editora Brasiliense, 1996.

CAMPEDELLI, Samira Youssef. Telenovela. 2. ed. São Paulo: Ática, 1987.

CANONGIA, Ligia. O legado dos anos 60 e 70. Rio de Janeiro: Jorge Zahar Ed., 2005.

DANIEL FILHO, 1937; LUZ, Sergio; MACIEL, Luiz Carlos. O circo eletrônico: fazendo tv no Brasil. 2. ed. rev. Rio de Janeiro: Jorge Zahar, 2003.

DESING, portal. Veja a nova identidade visual da Lukscolor criada por "Marina". Disponível em: <http://designbr.ning.com/profiles/blogs/veja-a-nova-identidade-visual->. Acesso em 30 de Outubro de 2011.

DONDIS, Donis A. Sintaxe da linguagem visual. 2. Ed. São Paulo: Martins Fontes, 1997.

EXTRA, portal. Saiba toda a história da próxima novela das 20h, 'Insensato coração'. Disponível em: < http://extra.globo.com/famosos/saiba-toda-historia-da-proxima-novela-das-20h-insensatocoracao-633165.html\#ixzz1acwBpiRy>. Acesso em 13 de outubro de 2011.

FARINA, Modesto. Psicodinâmica das cores em comunicação. 2ł. ed. São Paulo: Edgard Blücher, 1986.

FERREIRA, Maria Alice Silveira. Cultura de Massa, Televisão e Telenovela. Disponível em: $<$ http://www.jurisciencia.com/artigos/cultura-de-massa-televisao-e-telenovela/86/>. Acesso em: 02 de Outubro de 2011. 
JOLY, Martine. Introdução à análise da imagem. Campinas: Papirus, 1996. 152p.

KOTLER, Philip; KELLER, Kevin Lane. Administração de marketing. 12. ed. São Paulo, SP: Pearson Prentice Hall, 2006.

LUKSCOLOR, portal. Disponível em: <http://www.lukscolor.com.br/>. Acesso em: 15 de outubro de 2011.

MICHAELIS,

Dicionário.

Disponível

em:

http://michaelis.uol.com.br/moderno/portugues/index.php?lingua=portugues-

portugues \&palavra $=$ expressionismo $\& \mathrm{CP}=73075 \&$ typeToSearchRadio $=$ exactly $\&$ pagRadio $=50$.

Acesso em 15 de outubro de 2011.

MOURA, R.A., BANZATO, J.M., Embalagem: acondicionamento, unitização \& conteinerização Manual de movimentação de materiais. São Paulo: IMAM, 1990.

NEGRÃO, Celso; CAMARGO, Eleida. Design de embalagem: do marketing à produção. Novatec 2008.

PEIRCE, Charles Sanders. Semiótica. Trad: J. Teixeira Coelho Netto, Perspectiva, São Paulo, 1990.

POLIGNANO, L.A.C.; DRUMOND F.B. O papel da pesquisa de mercado durante o desenvolvimento de produtos. In: CONGRESSO BRASILEIRO DE GESTÃO DE DESENVOLVIMENTO DE PRODUTO, 3., 2001, Florianópolis. Anais... Florianóplis, 2001. 1CD.

ROMANO, L.N. Metodologia de Projeto para Embalagem. Florianópolis, 1996. Dissertação (Mestrado em Engenharia Mecânica) - Universidade Federal de Santa Catarina.

SANTAELLA, L. A assinatura das coisas. Rio de Janeiro: Imago, 1992.

SANTAELLA, Lúcia; NÖTH, Winfried. Imagem: cognição, semiótica, mídia. 4. ed. São Paulo, SP: Iluminuras, 2005.

SANTAELLA, Lúcia. O que é semiótica. São Paulo: Brasiliense, 1996. 
SANTAELLA, Lúcia. Semiótica Aplicada. São Paulo: Thomsom Learning, 2002.

SERPENTE, A garganta da. A linguagem. Disponível em: http://www.gargantadaserpente.com/linguagem/index.shtml. Acesso em 16 de dezembro de 2011.

SILVA, Jaqueline Arruda; ALMEIDA, Carlos C. de, Análise de embalagem e linguagem regional: aplicação da Semiótica peirciana no estudo de rótulos de embalagens de ervamate. UNI revista Vol.1, n: 3 jul 2006.

TELEDRAMATURGIA, portal.

Disponível em: <http://www.teledramaturgia.com.br/tele/home.asp>. Acesso em 11 de outubro de 2011. 